\title{
How accurate are methods for predicting phenology in New Zealand?
}

\author{
J.M. Kean \\ AgResearch Ltd, Ruakura Research Centre, East Street, Private Bag 3115, Hamilton 3240, \\ New Zealand \\ Corresponding author: john.kean@agresearch.co.nz
}

\begin{abstract}
Thermal accumulation ('degree day') methods are routinely used to predict plant and insect phenology. Depending on the data available, prediction may involve three separate steps with associated errors: estimating daily heat units from maximum and minimum temperatures; interpolating daily maxima and minima from monthly averages; and predicting future monthly averages from past climate, potentially including climate change. This research investigated the potential error in thermal accumulation totals arising from each of these factors at nine New Zealand sites. Ten simple heat unit calculations were tested, including two little-known and three new methods. Those utilising the true daily mean temperature performed best, followed by 4-step, triangle and sine approximations. Interpolating between monthly mean temperature extremes introduced much error into daily estimates, and the use of predicted, rather than observed, monthly normals further increased error. Specific recommendations are made for thermal accumulation methods depending on what temperature data are available.
\end{abstract}

Keywords temperature, climate, development, prediction error.

\section{INTRODUCTION}

Phenology models are widely used to predict the timing of plant growth events (e.g. bud break, flowering, harvest time) and insect life stages (e.g. oviposition, larval feeding, pupation, adult flights). They may underpin the prediction of crop maturation days (Wang 1960), the timing of management interventions in integrated pest management systems (Way \& van Emden 2000) and contribute to biosecurity risk assessments (e.g. Kean \& Kumarasinghe 2007). Most phenology models are based on the accumulation of physiological rather than calendar time, measured as degree days $\left({ }^{\circ} \mathrm{d}\right)$ above the minimum temperature that allows development to occur. While there are many problems with thermal accumulation methods (Wang 1960; Worner 1992), their accuracy is often sufficient for making important management decisions, at least when based on the actual temperatures experienced in the field. It is less clear how accurate thermal accumulation is for predicting future physiological events and/or beyond the current geographic range of a species.

Depending on the temperature data available, prediction may require three separate steps, each of which involves assumptions, extrapolations and the errors associated with these. First, heat units may need to be estimated from daily maximum and minimum temperatures. Many methods for doing so have been developed 
and tested under specific circumstances (e.g. Roltsch et al. 1999). This research trialled ten approaches, including two little-known (the 4-step and 4-step+ methods below) and three new ones developed here (the 3-step, 3-step+ and triangle + methods). Second, daily maximum and minimum temperatures are often unavailable, and must be interpolated from monthly averages; tests of three such approaches are presented here. Finally, when projecting into the future, monthly averages must be predicted from past climates. This was tested, with and without consideration of climate change across twenty years. For each combination of factors, the accuracy of thermal accumulation totals across nine representative New Zealand sites was assessed and the main sources of error identified. Recommendations are made on which thermal accumulation methods should be used to minimise potential error in phenology predictions for New Zealand.

\section{MATERIALS AND METHODS}

Hourly temperature data from 1 January 2008 to 31 December 2012 were obtained from NIWA's National Climate Database (http://cliflo.niwa. co.nz) for each of nine test locations: Whangarei $\left(35.769^{\circ} \mathrm{S}, \quad 174.364^{\circ} \mathrm{E}\right)$, Auckland $\left(37.008^{\circ} \mathrm{S}\right.$, $\left.174.789^{\circ} \mathrm{E}\right)$, Tauranga $\left(37.673^{\circ} \mathrm{S}, 176.196^{\circ} \mathrm{E}\right)$, Napier $\quad\left(39.461^{\circ} \mathrm{S}, \quad 176.859^{\circ} \mathrm{E}\right)$, Wellington $\left(41.322^{\circ} \mathrm{S}, \quad 174.804^{\circ} \mathrm{E}\right)$, Nelson $\left(41.302^{\circ} \mathrm{S}\right.$, $\left.173.219^{\circ} \mathrm{E}\right)$, Christchurch $\left(43.493^{\circ} \mathrm{S}, 172.537^{\circ} \mathrm{E}\right)$, Cromwell $\left(45.034^{\circ} \mathrm{S}, 169.196^{\circ} \mathrm{E}\right)$ and Dunedin $\left(45.929^{\circ} \mathrm{S}, 170.197^{\circ} \mathrm{E}\right)$. Missing data, comprising $0.14 \%$, were patched by interpolation (for gaps of up to 6 hours) or as the mean of the values for the same hour from the previous and subsequent days. Daily minimum, maximum and mean temperatures were calculated for each day and averaged for each month.

The analysis assumed linear development rates above a base temperature $b=10^{\circ} \mathrm{C}$, which is typical of many plants (Herms 2004) and arthropods (Jarošík et al. 2011). The 'true' daily heat units $D$ (in degree days, ${ }^{\circ} \mathrm{d}$ ) were obtained from hourly temperatures $T_{h}$ (in ${ }^{\circ} \mathrm{C}$ ) as $D=\left[T_{h}-b\right] / 24$. Here, and below, quantities within square brackets are rounded up to 0 if negative. Estimated daily heat units $d$ (in ${ }^{\circ} \mathrm{d}$ ) may be derived from daily maximum and minimum temperatures $T_{\max }$ and $T_{\min }$ in several ways. In the formulae below, $m$ is the nominal mean temperature $\left(T_{\max }+T_{\min }\right) / 2$, and $a$ is the semiamplitude of daily temperature fluctuations $\left(T_{\max }-T_{\min }\right) / 2$. The methods tested were:

- The 'average method' (McMaster \& Wilhelm 1997) effectively assumes that the daily temperature is constant at $m$, thus $d=[m-b]$. When the true mean daily temperature $T_{\text {mean }}$ is known, for example from hourly data, then the 'average+' methods uses this in place of $m$.

- The '2-step approximation', sometimes referred to as the 'modified average method' (Herms 2004) effectively models half a day at the maximum temperature and half at the minimum: $d=\left(\left[T_{\max }-b\right]+\left[T_{\min }-b\right]\right) / 2$.

- The '3-step' approximation is presented here for the first time, and assumes that the temperature is at $T_{\max }, T_{\min }$ and $m$ for one third of the day each, thus $d=\left(\left[T_{\max }-b\right]+\left[T_{\min }-b\right]+[m-b]\right) / 3$. The new '3-step+' method uses $T_{\text {mean }}$ in place of $m$.

- The '4-step', or 'trapezoidal' approximation (Barlow \& Dixon 1980) assumes that the temperature is $T_{\max }$ for a quarter of the day, $T_{\min }$ for quarter of the day, and $m$ for half of the day, thus $d=\left(\left[T_{\max }-b\right]+\left[T_{\min }-b\right]+2[m-b]\right) / 4$. The '4-step+' method uses $T_{\text {mean }}$ in place of $m$.

- The 'triangle approximation' (Lindsey \& Newman 1956) assumes that maximum and minimum daily temperatures occur exactly twelve hours apart and that temperature tracks in a straight line from one to the other. Thus, if $T_{\min } \geq b$ then $d=(m-b)$, else $d=\left[T_{\max }-b\right]^{2} / 4 a$. The new 'triangle+' method uses $T_{\text {mean }}$ as follows: apply the triangle method calculation with $T_{\text {mean }}$ substituted for $T_{\max }$ (including in $m$ and a); repeat with $T_{\text {mean }}$ instead substituted for $T_{\text {min }}$; finally, take the arithmetic mean of these two results.

- The 'sine approximation' (Baskerville \& Emin 1969) assumes that temperatures follow a sine curve through the day, peaking at $T_{\max }$ and troughing at $T_{\min }$. Thus, if $T_{\max } \leq b$ then $d=0$, else if $T_{\min } \geq b$ then $d=[m-b]$, 
else $d=((m-b)(\pi / 2-\theta)+a \cdot \cos (\theta)) / \pi$, where $\theta=\sin ^{-1}((b-m) / a)$.

Each of these methods is illustrated in Figure 1. All except the "+" methods assume that daily temperature is symmetrical around $m$, and all give $d=(m-b)$ when $T_{\text {min }} \geq b$. Therefore, the choice of method becomes less important as temperatures increase or the base temperature $b$ becomes smaller. "Double" versions of the triangle and sine approximations may be used to smooth the estimates from one day to the next (Allen 1976), but these tend not to perform any better (Roltsch et al. 1999). More complex simulation methods are also available (Worner 1988; Cesaraccio et al. 2001), but these require calibration for particular sites and years, so are rarely used except in detailed models for specific situations.

Monthly mean values were derived from the daily temperature extremes at each site. These were then used to interpolate back to daily values using the following methods (illustrated in Figure 2):

- 'Stepwise' interpolation assumed that the monthly mean values applied for each day of that month.

- 'Linear' interpolation assumed that the monthly means occurred on the $15^{\text {th }}$ of each month, with daily values interpolated along a straight line joining the previous and next mid-month values.

- 'Spline' interpolation also assumed mean values to occur mid month, but daily values were interpolated according to a cubic spline fitted through the whole 5-year dataset.

Predicted monthly means were derived from NIWA's spatially interpolated climate data for New Zealand at $5 \mathrm{~km}$ resolution (Tait et al. 2006). The base period for these data is 19801999 (nominally 1990), with further predictions provided for 2030-2049 (nominally 2040) from a set of twelve global climate models under a range of climate change scenarios. To obtain values for 2008-2012, linear interpolation between 1990 and 2040 values was used, assuming moderate carbon emission (IPPC scenario Alb). The resulting monthly estimates for $T_{\min }$ and $T_{\max }$ were interpolated to daily values and thermal summations applied as described above.

Regression methods (Piñeiro et al. 2008) were used to compare actual daily thermal accumulations $D$ (on theY-axis) against estimated values $d$ (on the $\mathrm{X}$-axis). Each combination of site, summation method, interpolation method and data source (actual, historical, or climate change predicted) was characterised by the mean error

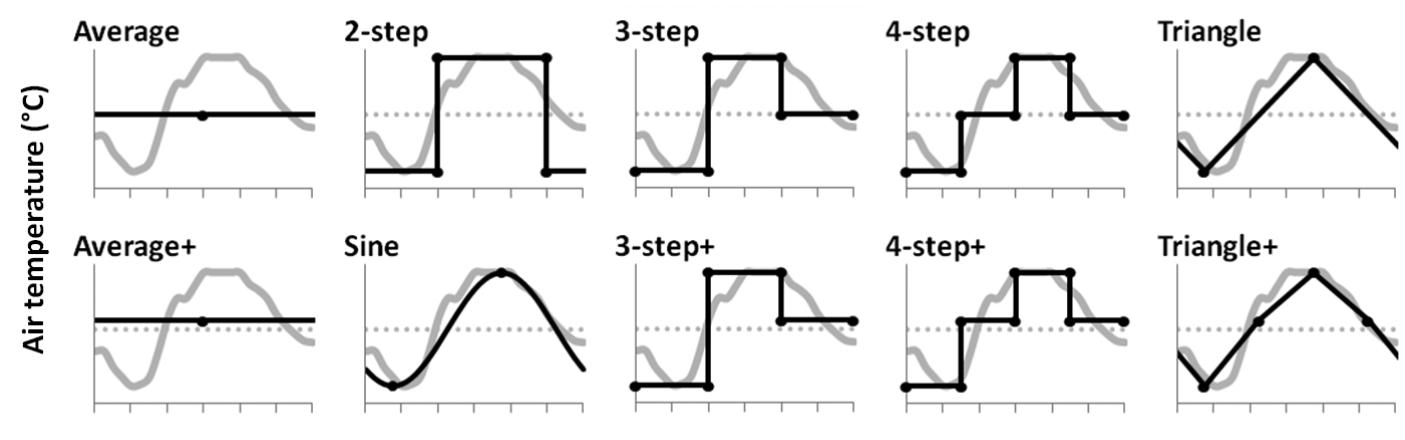

Hours after midnight

Figure 1 Conceptual illustration of the thermal summation models investigated. The grey line indicates a typical temperature profile through the day (in this case Christchurch on 5 January 2008), with $T_{\max }$ $=21.0^{\circ} \mathrm{C}, T_{\text {min }}=8.0^{\circ} \mathrm{C}$ and $T_{\text {mean }}=15.5^{\circ} \mathrm{C}$. The dotted line indicates the nominal mean temperature $\mathrm{m}$ $=14.5^{\circ} \mathrm{C}$. 

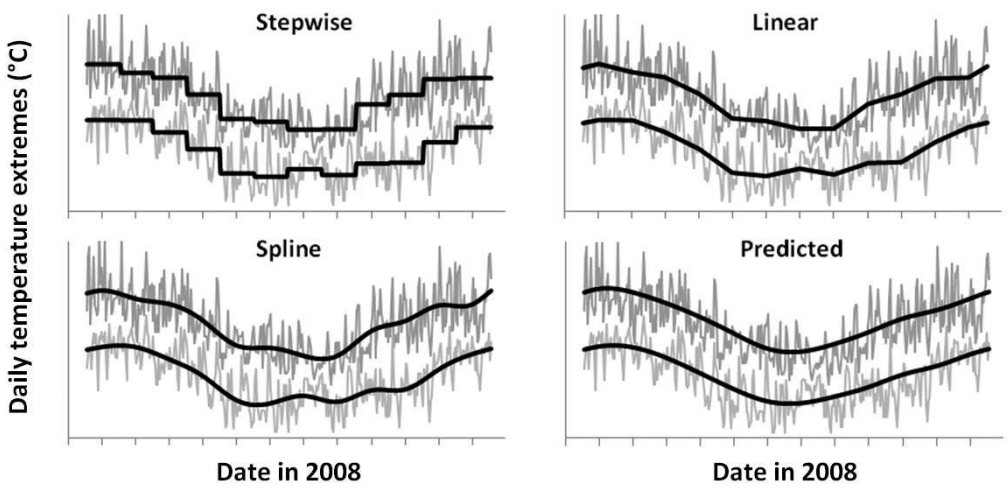

Figure 2 Illustration of methods for extrapolating daily temperature extremes. Grey lines show the actual daily maximum and minimum temperatures (from Christchurch in 2008) and black lines show values interpolated from monthly means. In the last case, labelled "Predicted", the monthly means for 2008 were forecast from 1980-1999 means using NIWA's 12-model prediction for climate change under moderate emissions (scenario A1b).

in daily thermal accumulation $(d-D$, a measure of accuracy), and by the root mean squared deviation of $D$ versus $d$ (a measure of precision, similar to the standard deviation of daily errors). Since there were over 600 different combinations of test factors, only a representative subset of the results is presented below.

\section{RESULTS}

The best estimates of daily thermal accumulation were obtained using the 4-step+ and triangle+ methods, which utilised true daily means (Figures 3 \& 4). Of those methods that used only the observed daily extremes (maximum and minimum temperatures), the 4 -step, triangle and sine methods all performed well, with little difference between them. The average and average + methods tended to underestimate daily thermal accumulation, while the 2-step method overestimated it. All methods performed better at northern (warmer) locations than at southern (cooler) ones (Figure 4), and within sites the estimates were best for relatively warm days.

The errors arising from different thermal accumulation methods were of a much smaller magnitude than those introduced by the use of monthly averages (Figures $5 \& 6$ ). The method used for interpolating between monthly values had relatively little influence on accuracy or precision, but splining was slightly better than

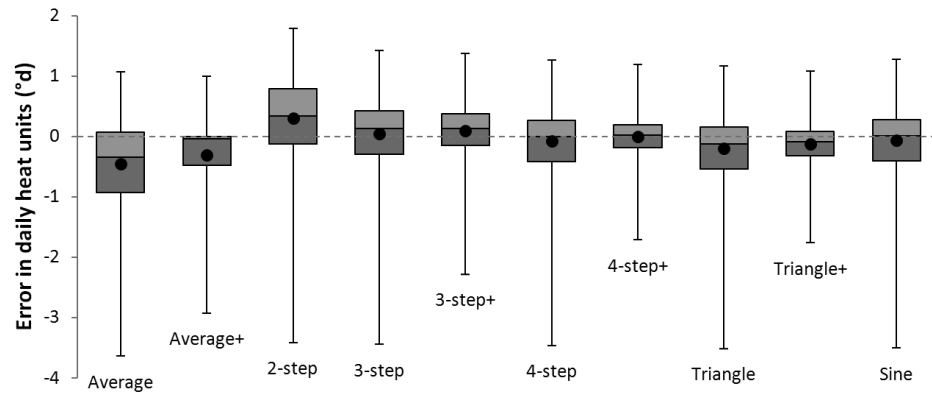

Figure 3 Box plot of errors in daily heat units calculated from actual daily temperature extremes and means in Napier from 1 January 2008 to 31 December 2012. Boxes show first, second (median) and third quartiles, dots indicate means, and whiskers extend to maximum and minimum values. 


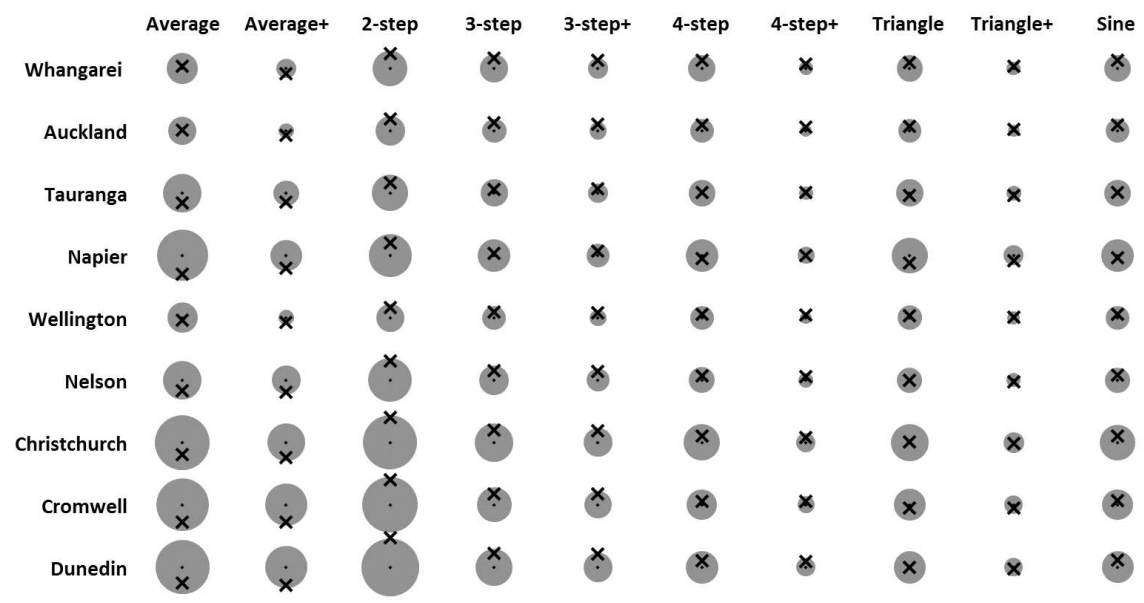

Figure 4 Target chart for the performance of thermal summation methods using observed daily temperature extremes from 1 January 2008 to 31 December 2012. Radius of each grey circle is proportional to the root mean squared deviations (indicative of error variance), while position of crosses relative to circle centres is proportional to mean error (above or below indicating over- or underestimation, respectively). Best performance is indicated by the smallest circle with its cross closest to the centre.

a linear interpolation, and both were better than the stepwise method. Variance decomposition suggested that when predicting degree day accumulations using the 4-step approximation together with linear interpolation at the nine test sites, around $8 \%$ of the total error is associated with the use of daily maximum and minimum temperatures, $75 \%$ can be attributed to the use of monthly mean temperatures, and $17 \%$ is associated with the prediction of these monthly means. Taking climate change across a 20 -year period into account reduced error by only around $2 \%$.

To put these results into context, consider that the mean generation time for a hemipteran is around $363{ }^{\circ} \mathrm{d}$, while that for a lepidopteran is around $559^{\circ} \mathrm{d}$ (Nietschke 2007). In Napier, using actual daily temperature extremes and the 4-step method, predicted development times are accurate to within about a day (mean prediction error for Hemiptera: 0.5 days, $90^{\text {th }}$ percentile range $=-4$ to 3 days; Lepidoptera: $1.3,-3$ to 4 ). However, if linear interpolation is used between adjusted monthly means, then the mean errors in predicted development time are in the order of a week (Hemiptera: mean $=-7.6$ days, $90^{\text {th }}$ percentile range $=-24$ to 2 days; Lepidoptera: $-8.9,-24$ to 2 ).

\section{DISCUSSION}

Agronomists most commonly use the average and 2-step methods for predicting plant phenology (Pruess 1983; Herms 2004), although it is clear that these are relatively inaccurate (Figure 4). McMaster \& Wilhelm (1997) showed that these methods, while often confused, may result in very different thermal sums. Herms (2004) recognised that the 2-step method will suggest a higher number of degree days, but his assertion that it is therefore more accurate was not supported here. Indeed, the present results demonstrate that while the average method underestimates heat units, the 2-step method tends to overestimate them by a similar magnitude (Figures $3 \& 4$ ). This may explain why the 4-step method, which is equivalent to the arithmetic mean of the average and 2-step methods, performed so well.

Although the 4-step method was first published by Barlow \& Dixon (1980) over 30 


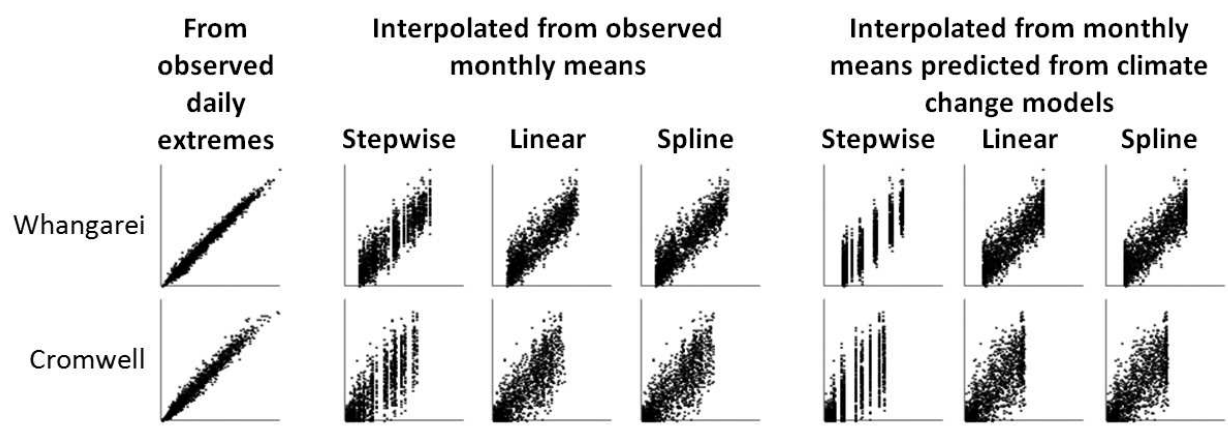

Figure 5 Plots of actual (Y-axis) versus estimated (X-axis) daily heat units $\left({ }^{\circ} \mathrm{d}\right)$, using the 4-step method applied to observed or interpolated daily temperature extremes from two locations from 1 January 2008 to 31 December 2012.

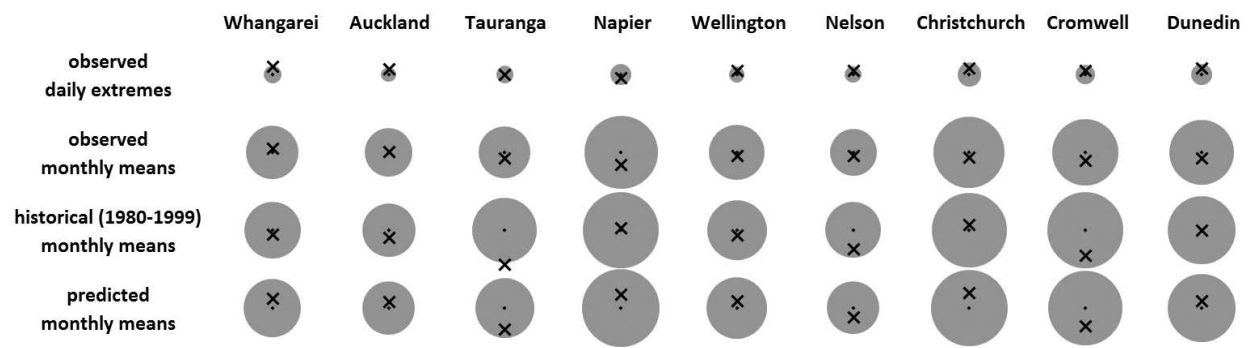

Figure 6 Target chart showing errors in predicted daily heat units ( $\left.{ }^{\circ} \mathrm{d}\right)$ for 2008 to 2012 from the 4-step method applied to observed daily temperature extremes (top row) and from linear interpolation between actual monthly means (second row), historical monthly means (third row), and monthly means predicted from climate change models (bottom row). Best performance is indicated by the smallest circle with its cross closest to the centre.

years ago, it has not been widely adopted, perhaps because its performance had not previously been quantified. It has now been shown that for New Zealand climates the 4-step method has very similar accuracy to the more computationally demanding triangle and sine methods that are favoured by entomologists (e.g. Roltsch et al. 1999). An additional benefit of the 4-step method is that it can utilise daily mean temperatures, when available, to outperform the standard sine and triangle methods, though the new triangle+ method performs similarly well. The 'step'-based methods are also very easy to use with nonlinear development rates, simply by replacing the square-bracketed terms with the proportion of development achieved per day at the appropriate temperature (Barlow et al. 2000). In contrast, the triangle and sine methods become unwieldy with non-linear development rates.

The present results supported previous New Zealand work suggesting that the accuracy of heat unit predictions is lowest in relatively cool (southern) areas, and in local climates subject to rapid heating or cooling effects such as föhn winds and cold fronts (Worner \& Penman 1983; Worner 1988). However, the error associated with daily thermal accumulation calculations was dwarfed by that arising from the interpolation of daily extremes from monthly normals (Figures 5 \& 6). This aspect of thermal summation had not previously been investigated, but it is clearly of concern when daily data are unavailable. One potential mitigation is to simulate realistic daily variation in temperature extremes by deriving 
suitable stochasticity parameters from historical climate data (Régnière \& Bolstad 1994), but this may be impractical in some situations. At the very least, researchers and decision-makers should recognise the relative importance of different sources of error in phenological predictions.

Based on these results, the following approaches to thermal accumulation are recommended, depending on what temperature data are available: 1. Use actual hourly temperature recordings, when available.

2. Otherwise, use the 4-step+ or triangle+ summation methods with actual daily maximum, minimum, and mean temperatures.

3. Otherwise, use the 4-step, triangle or sine methods with actual daily maximum and minimum temperatures, recognising that climates that are cool relative to the base temperature for development, or where hourly temperature profiles are highly asymmetric, will be subject to the greatest prediction error.

4. If forced to interpolate daily temperature extremes from monthly normals, use linear or spline interpolation together with the 4-step, triangle or sine methods. Recognise that considerable error is involved (up to 10 times more than if actual daily temperature extremes are available) and consider whether simulating realistic variability in daily extremes is apposite.

5. Acknowledge additional uncertainty associated with predicting into the future, where temperatures can only be estimated. Model performance may be improved by including climate change projections, though the benefits may be minor for predictions less than 20 years out.

\section{ACKNOWLEDGEMENTS}

I am grateful to Kumar Vetharaniam, Peter Lo and Sue Zydenbos for helpful feedback, and to New Zealand's National Institute of Water and Atmospheric Research (NIWA) for sharing their climate data. This work was supported by the Ministry for Primary Industries RFP 15184 and by the Better Border Biosecurity (B3) cooperative research programme (b3nz.org), which is partly funded through AgResearch's core funding received from the Ministry of Business, Innovation and Employment (MBIE).

\section{REFERENCES}

Allen JC 1976. A modified sine wave method for calculating degree days. Environmental Entomology 5: 388-396.

Barlow ND, Caldwell NP, Kean JM, Barron MC 2000. Modelling the use of NPV for the biological control of Asian gypsy moth Lymantria dispar invading New Zealand. Agricultural and Forest Entomology 2: 173-184.

Barlow ND, Dixon AFG 1980. Simulation of lime aphid population dynamics. Pudoc, Wageningen. $165 \mathrm{p}$.

Baskerville GL, Emin P 1969. Rapid estimation of heat accumulation from maximum and minimum temperatures. Ecology 50: 514.

Cesaraccio C, Spano D, Duce P, Snyder RL 2001. An improved model for determining degreeday values from daily temperature data. International Journal of Biometeorology 45: 161-169.

Herms DA 2004. Using degree-days and plant phenology to predict pest activity. In: Krischik V, Davidson J ed. IPM of Midwest Landscapes. University of Illinois, USA. Pp. 49-59.

Jarošík V, Honěk A, Magarey RD, Skuhrovec J 2011. Developmental database for phenology models: related insect and mite species have similar thermal requirements. Journal of Economic Entomology 104: 1870-1876.

Kean JM, Kumarasinghe L 2007. Predicting the seasonal phenology of fall webworm (Hyphantria cunea) in New Zealand. New Zealand Plant Protection 60: 279-285.

Lindsey AA, Newman JE 1956. Use of official weather data in spring time: temperature analysis of an Indiana phenological record. Ecology 37: 812-823.

McMaster G, WilhelmWW 1997.Growing degreedays: one equation, two interpretations. Agricultural and Forest Meteorology 87: 291-300. 
Nietschke BS, Magarey RD, Borchert DM, Calvin DD, Jones E 2007. A developmental database to support insect phenology models. Crop Protection 26: 1444-1448.

Piñeiro G, Perelman S, Guerschman JP, Paruelo JM 2008. How to evaluate models: observed vs. predicted or predicted vs. observed? Ecological Modelling 216: 316-322.

Pruess KP 1983. Day-degree methods for pest management. Environmental Entomology 12: 613-619.

Régnière J, Bolstad P 1994. Statistical simulation of daily air temperature patterns in eastern North America to forecast seasonal events in pest management. Environmental Entomology 23: 1368-1380.

Roltsch WJ, Zalom FG, Strawn AJ, Strand JF, Pitcairn MJ 1999. Evaluation of several degree-day estimation methods in California climates. International Journal of Biometeorology 42: 169-176.

Tait A, Henderson R, Turner R, Zheng X 2006. Thin plate smoothing spline interpolation of daily rainfall for New Zealand using a climatological rainfall surface. International Journal of Climatology 26: 2097-2115.
Wang JY 1960. A critique of the heat unit approach to plant response studies. Ecology 41: 785.

Way M, van Emden H 2000. Integrated pest management in practice - pathways towards successful application. Crop Protection 19: 81-103.

Worner SP, Penman DR 1983. Analysis of thermal summation models. Proceedings of the $36^{\text {th }}$ New Zealand Weed and Pest Control Conference: 250-254.

Worner SP 1988. Evaluation of diurnal temperature models and thermal summation in New Zealand. Journal of Economic Entomology 81: 9-13.

Worner SP 1992. Performance of phenological models under variable temperature regimes: consequences of the Kaufmann or rate summation effect. Environmental Entomology 21: 689-699. 